\title{
Acculturation of immigrant diet, basic taste responses and sodium appetite
}

\author{
Micah Leshem* and Haymanot Dessie-Navon \\ Psychology Department, University of Haifa, Haifa, 3498838, Israel \\ (Received 8 February 2018 - Final revision received 8 April 2018 - Accepted 22 June 2018) \\ Journal of Nutritional Science (2018), vol. 7, e21, page 1 of 11
}

doi:10.1017/jns.2018.12

Abstract

In young new Ethiopian immigrants (EI, about 0.5 years since immigration; $n 20)$, veteran Ethiopian immigrant students (ES, about 13 years since immigration; $n$ 30) and native Israeli students (NS; $n$ 82), dietary macronutrients and electrolytes, and responses to basic tastes were compared in a cross-sectional design. From EI, to ES, to NS, dietary energy, protein, fat, and $\mathrm{Na}^{+}$increase, whereas carbohydrates, $\mathrm{K}^{+}$and $\mathrm{Ca}^{2+}$ do not differ. Corrected for energy intake, only $\mathrm{Na}^{+}$increases. EI consume less dietary $\mathrm{Na}^{+}$, like foods with less $\mathrm{Na}^{+}$content, salt their food less, yet show a greater hedonic response to salt taste. In contrast, preference for sweet does not differ. Taste psychophysics, $6-n$-propylthiouracil (PROP) responses and lingual fungiform papillae density differ by group (and sex), but do not relate to dietary intake. Together, these changes could reflect dietary acculturation, increasing overall intake, $\mathrm{Na}^{+}$in particular, accompanied by decreasing taste sensitivity, and changes in sensory perception and preference in these Ethiopian immigrants. The fact that immigrants find salt more hedonic, yet eat less of it, could suggest increased sensitivity to its taste, and might suggest restoring sensitivity to reduce $\mathrm{Na}^{+}$intake for all. Similar alterations in taste sensory responses might be obtained in other forms of dietary flux. Understanding dietary acculturation can focus efforts (e.g. on $\mathrm{Na}^{+}$), to anticipate the disease burden of diets of affluence among immigrants. Yet, these immigrants' nutrition is healthier in its low fat and $\mathrm{Na}^{+}$, suggesting that nutritional advice should focus on preservation, as well as prevention. Our study adds Ethiopian nutritional acculturation to that of the varied immigrant groups around the world.

Keywords: Basic tastes: Dietary acculturation: Ethiopian immigrants: Lingual papillae: 6- $n$-Propylthiouracil (PROP): Salt appetite: Sex differences

Immigration often imposes far-reaching changes in nutrition. In particular, immigration to affluent societies with richer and more varied diets is often associated with increased energy, fat and $\mathrm{Na}^{+}$intake, and compromised health. This includes diabetes, hypertension and obesity, which have been reported for Ethiopian immigrants to Israel; however, surprisingly, alteration in $\mathrm{Na}^{+}$intake, which is implicated in these and other ailments, has been largely neglected ${ }^{(1-12)}$.

Changes in diet are accompanied by changes in preference, but there have been no studies of the sensory changes accompanying dietary acculturation ${ }^{(13)}$. Differences in taste responses have been related to sex, age, BMI, genetics (e.g. sensitivity to the taste of 6-n-propylthiouracil (PROP)) and lingual papilla density. These have been postulated to influence food choice, energy intake, and, ultimately, body weight and health, and thus may contribute to immigrant dietary acculturation and health ${ }^{(14-26)}$.

Here, in a cross-sectional design, we compared young, new (about 6 months) Ethiopian immigrants (EI), about 13 years veteran Ethiopian immigrant students (ES) and native Israeli students (NS), documenting differences in diet composition and taste responses, to suggest a longitudinal perspective on immigrant dietary and sensory acculturation. We evaluated dietary macronutrient and electrolyte intake, taste responses to intensity and hedonics of four basic tastes $(\mathrm{NaCl}$, citric acid, sucrose and quinine $\mathrm{HCl}$ ), PROP taster status and

Abbreviations: EI, new Ethiopian immigrant; ES, veteran Ethiopian immigrant student; NS, native Israeli student; MANCOVA, multivariate ANCOVA; PROP, 6- $n$-propylthiouracil; VAS, visual analogue scale.

* Corresponding author: Micah Leshem, email micahL@psy.haifa.ac.il 
density of anterior lingual fungiform papilla (except in EI). Because of its relation to hypertension in immigrants ${ }^{(1,10)}$, we focused on salt appetite, the predilection for salt expressed in the variety of ways it is ingested.

\section{Materials and methods}

\section{Participants}

A total of eighty-two undergraduate NS and thirty undergraduate ES aged 18-33 years in the University of Haifa were recruited by posted notices. Twenty EI of similar age in an immigrant 'absorption centre ${ }^{\text {(27) }}$ agreed to participate. Availability of immigrants matching the group criteria constrained group size and sex ratio (Table 1).

The university institutional review board provided ethics approval, and participants were advised to omit questions or tests they preferred. That, and missing data, varied sample sizes.

EI were not proficient in Hebrew, and were tested in Amharic, by Amharic-speaking researchers.

Participants were requested not to eat, drink (except water) or smoke for $1 \mathrm{~h}$ prior to the test session, which lasted some $90 \mathrm{~min}$. At the end of the session weight and height were recorded.

Participants received credits or the equivalent of about $\$ 10$ in shekels, by choice.

\section{Background questionnaire}

The questionnaire queried age, dietary restrictions, smoking frequency, physical activity and phase of menstrual cycle. For EI, socio-economic status cannot be compared because it was determined by the absorption centre where they lived and received all basic requirements. ES and NS were identical in university educational level. Economic status (scholarships, parental income) was not queried.

\section{Dietary intake, seasoning, and liking questionnaire}

Respondents reported the previous $7 \mathrm{~d}$ frequency and amount of consumption of some seventy-six items of food and drink (including items the participants added) covering the Israeli diet and available Ethiopian foods. This was analysed for dietary energy, macronutrient, electrolyte and water content. Each item was scored for liking on a five-level scale ( -2 'dislike intensely', 0 neutral, +2 'like very much') ${ }^{(28-30)}$. Seasoning was scored on a four-level ordinal scale. Only salt and sugar are analysed here.

\section{Psychophysical assessment of hedonics and intensity of basic} tastes

Intensity and hedonics were evaluated with oral sprays and visual analogue scales (VAS). Using perfume bottles, the experimenter sprayed a single pulse of $0.29 \mathrm{ml}$ of each taste concentration in fixed and counterbalanced semi-randomised orders (excluding sequential concentrations) into each participant's mouth. Using VAS, participants rated (horizontal on-screen slider) each concentration for taste intensity ('how strong is the taste?', in Hebrew) anchored by 'don't feel anything' and 'very strong', and on a separate screen, hedonics ('how tasty is it?') anchored by 'not tasty' and 'very tasty $^{\text {(28-30) }}$. For the new immigrants, instructions and questions were explained in Amharic.

Six concentrations of $\mathrm{NaCl}(2.5 \mathrm{~mm}-2.56 \mathrm{~m}$ by quadruple dilution steps), sucrose $(0 \cdot 1-27 \%$ (w/v), treble steps), citric acid $(1 \cdot 2-280 \mathrm{~mm}$, treble steps), and quinine $\mathrm{HCl}(0 \cdot 01-0 \cdot 35$ $\mathrm{mm}$, double steps) were tasted (Fig. 3). Participants rinsed their mouths between concentrations with distilled water. The order of taste testing was $\mathrm{NaCl}, \mathrm{HCl}$, sucrose and quinine (tested last to avoid carry-over effects). Taste tests were separated by $10 \mathrm{~min}$ of questionnaire.

Concentration-response served for the taste analyses, and the mean of the three highest concentrations (superscripted ${ }^{456}$ ), as suprathreshold responses, served for correlations (Table 2, Figs 2, 3 and 4) ${ }^{(28-30)}$.

As a cross-modal control to test whether instructions for the VAS were understood across groups, $62 \mathrm{~cm}$ squares of greyscale gradations between white and black, presented in random order, were scored for how 'black' they were (Fig. 2(c) and (f) $)^{(29)}$.

Table 1. Demographics and taste characteristics (Mean values with their standard errors)

\begin{tabular}{|c|c|c|c|c|c|c|}
\hline & \multicolumn{2}{|c|}{$\begin{array}{l}\text { New Ethiopian immigrants } \\
\qquad(n 17-20)\end{array}$} & \multicolumn{2}{|c|}{$\begin{array}{l}\text { Veteran Ethiopian immigrant } \\
\text { students }(n 28-30)\end{array}$} & \multicolumn{2}{|c|}{$\begin{array}{l}\text { Native Israeli students } \\
\text { ( }(\text { 76-82) }\end{array}$} \\
\hline & Mean & SE & Mean & SE & Mean & SE \\
\hline Age (years) & $.20 \cdot 6^{\star *}$ & 0.7 & 23.6 & 0.3 & $22 \cdot 7$ & 0.3 \\
\hline BMI $\left(\mathrm{kg} / \mathrm{m}^{2}\right)$ & $20 \cdot 8$ & 0.4 & $21 \cdot 3$ & 0.6 & $22 \cdot 8^{\star}$ & 0.4 \\
\hline Women $(n) \ddagger$ & \multicolumn{2}{|c|}{5} & \multicolumn{2}{|c|}{21} & \multicolumn{2}{|c|}{59} \\
\hline Time since immigration (years) & 0.48 & 0.04 & $13 \cdot 13^{\star \star}$ & 0.94 & - & \\
\hline Activity score & $7 \cdot 1$ & 0.9 & $6 \cdot 1$ & 0.5 & $7 \cdot 3$ & 0.4 \\
\hline Cigarettes (no./d) & 0.3 & 0.3 & $3.8 \dagger$ & 1.4 & $2 \cdot 2$ & 0.6 \\
\hline Papilla density & - & - & $12 \cdot 3^{*}$ & $1 \cdot 1$ & 15.5 & 0.7 \\
\hline PROP & $67.7^{\star}$ & 8.4 & 59.4 & $5 \cdot 6$ & $50 \cdot 2$ & $3 \cdot 1$ \\
\hline Taster type (\%) & \multicolumn{2}{|c|}{$12,35,53$} & \multicolumn{2}{|c|}{$13,47,40$} & \multicolumn{2}{|c|}{$13,62,24$} \\
\hline
\end{tabular}

PROP, 6-n-propylthiouracil.

Different from unmarked groups: * $P<0.05,{ }^{* *} P<0.01$.

$\dagger$ Different from new Ethiopian immigrants $(P=0.013)$.

$\ddagger P<0.001\left(\chi^{2}(2)=16\right)$. 


\section{Sweet and salty tidbits}

After the taste tests, while completing the questionnaires, two familiar, commercial, salty (890 and $780 \mathrm{mg} / 100 \mathrm{~g} \mathrm{Na}^{+}$) and sweet $\left(120.5\right.$ and $\left.146 \mathrm{mg} / 100 \mathrm{~g} \mathrm{Na}^{+}\right)$snack items in bite-size tidbits on separate saucers were placed on the tabletop near the participants, who were invited to freely eat of them. The number and type of tidbits eaten was recorded discreetly ${ }^{(28-30)}$. A cup of water was also presented.

\section{Preferred concentration of $\mathrm{NaCl}$ in soup, and sugar in tea}

The test is based on that used by Stone \& Pangborn ${ }^{(31)}$. Tomato soup was prepared by diluting pure tomato paste concentrate $\left(22^{\circ} \mathrm{Bx}\right.$; Sanlakol) with nine parts water. Participants were presented with two $100 \mathrm{ml}$ cups of hot (about $45 \pm 5^{\circ} \mathrm{C}$ ) tomato soup, one unsalted and one with $3 \cdot 0 \%$ (w/v) $\mathrm{NaCl}$. The word 'salt' was not used; the participants were asked to taste the 'flavoured' and the 'unflavoured' cup of soup, and then, using a $5 \mathrm{ml}$ teaspoon, mix them into a third cup, into which the researcher had poured some of the unflavoured soup, until the soup was 'most tasty'. The $\mathrm{Na}^{+}$content of the mixture was determined. The procedure for determining the preferred concentration of sugar in tea was similar, with one cup containing unsweetened tea, and the other tea with $20 \%$ (w/v) sucrose $\mathrm{s}^{(28-30)}$.

\section{Evaluation of salt appetite}

Dietary $\mathrm{Na}^{+}$and salting, from the dietary questionnaire, hedonics of salt scored as the mean of the three highest concentrations of $\mathrm{NaCl}$ oral sprays, number of salty tidbits eaten, and preferred concentration of salt in soup were ranked and summed to provide an unweighted mean 'salt appetite' score. Analogous four measures for sweet (there is no measure of dietary 'sweet'), provided the control 'sweet preference $^{\text {,(28,30,31) }}$.

\section{Biography of putative sodium loss}

Dehydrational events during the lifetime of the participants were queried, and participants posted a questionnaire to their mothers querying the frequency, and severity, of nausea and vomiting by trimester while pregnant with the participant ${ }^{(28-30,32-35)}$. Most EI mothers were not available.

\section{6-n-Propylthiouracil responses and taster type}

Participants tasted a filter disc impregnated with $0.025 \mathrm{mg}$ PROP (kindly donated by Linda Bartoshuk), scaled their sensation of intensity on a labelled magnitude scale, and were classified as super tasters, tasters or non-tasters ${ }^{(36)}$.

\section{Papilla density}

Density of fungiform papillae in the anterior tongue was assessed using blue food colouring, and pressing to the tongue a plastic microscope slide with two glued $7 \mathrm{~mm}$ diameter binder punch-holes. The two punch-hole areas were centred
$5.5 \mathrm{~mm}$ either side of the midline and photographed ${ }^{(36,37)}$. Counting was blind to group. Papilla density on the two sides correlated $(0.898 ; P<0.000)$, so their mean served for the analyses. Papillae were not counted in EI for whom the procedure was too invasive.

\section{Statistical methods}

Based on a previous study ${ }^{(29)}$, power for EI-NS and EI-ES comparisons for dietary macronutrients exceeds $99 \%$, and for $\mathrm{Na}^{+}, 94$ and $82 \%$, respectively (unequal group sizes, 20/80 and 20/30, two-sided tests, $5 \%$ significance level), suggesting the sample sizes are adequate for reasonable confidence in the dietary comparisons.

Multivariate (mixed between-within) ANCOVA (MANCOVA), or univariate analyses of covariance, adjusted for smoking (which can affect basic taste sensation ${ }^{(38,39)}$ ), age and BMI, because they differed significantly (Table 1), ANOVA, followed by the least significant difference (LSD) test for post hoc comparisons (general linear model), the Kruskall-Wallis test, as appropriate, and the Spearman correlation coefficient with Benjamini-Hochberg correction with $Q$ $=0.25$ were used. Probabilities over 0.05 (two-tailed) were not considered significant or detailed; the standard error of the mean is the measure of variability throughout (IBM SPSS 23 statistical package).

\section{Results}

Dietary intake, seasoning, and liking questionnaire

MANCOVA of seven dietary components (three macronutrients, three electrolytes, energy) by group and sex revealed an interaction of group and dietary nutrient $(F(12,726)=5 \cdot 7 ; P$ $<0.000)$ and a group effect $(F(2,121)=6.6 ; P<0.002)$. Subsequent univariate ANCOVA for individual nutrients showed group differences for dietary energy $(F(2,121)=4 \cdot 3$; $P=0 \cdot 016)$, protein $(F(2,121)=3 \cdot 4 ; P=0 \cdot 037)$, fat $(F(2,122)$ $=7 \cdot 1 ; \quad P=0 \cdot 001)$ and $\mathrm{Na}^{+}(F(2,122)=8 \cdot 1 ; \quad P=0 \cdot 001)$. Carbohydrates, $\mathrm{Ca}^{2+}, \mathrm{K}^{+}$, group and sex differences were not significant (Fig. 1).

Of the covariates, smoking increased dietary intake, specifically energy, fat, $\mathrm{Na}^{+}$and alcohol (not detailed).

To further examine the group differences each macronutrient and electrolyte was analysed by group and sex controlling for energy and the other five dietary components (as well as age, smoking and BMI). A group effect was only found for $\mathrm{Na}^{+}(F(2,115)=3.33 ; P=0 \cdot 039)$, suggesting that the increase in $\mathrm{Na}^{+}$intake across groups was at least partially independent of other dietary components. Post hoc tests confirmed that EI ingested less $\mathrm{Na}^{+}$than NS $(P=0 \cdot 027$; Fig. 1).

Adding salt, but not sugar, differed by group $(F(2,118)=$ 4.4; $P=0 \cdot 014$ ), EI adding less salt than ES and NS (Table 2).

EI showed an inverse correlation between liking scores and $\mathrm{Na}^{+}$content of seventy-two food items $\left(r_{\mathrm{s}}-0.395 ; P=0.0009\right)$.

Alcohol intake did not differ by group: $21.7 \%$ of men and $35.7 \%$ of women drank no alcohol. 


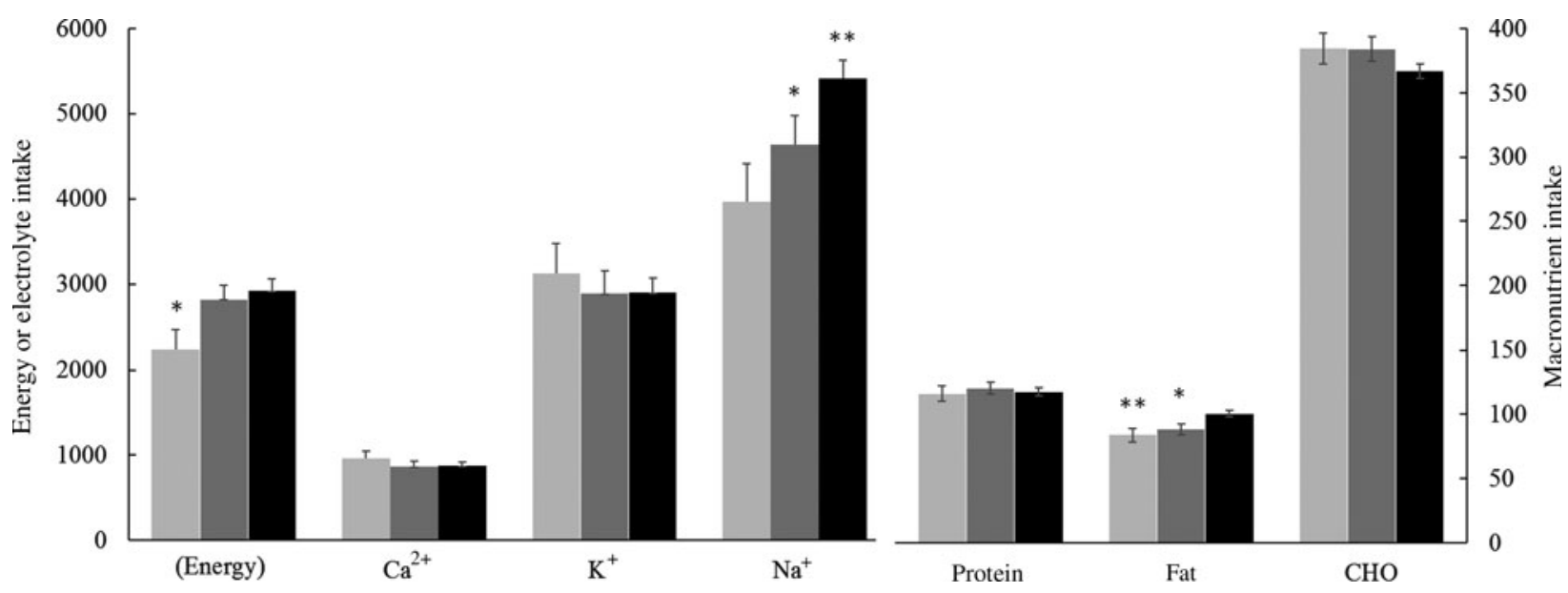

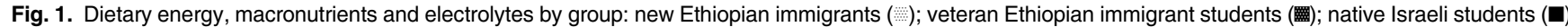
Values are means, with standard errors represented by vertical bars. Different from unmarked bars: ${ }^{*} P<0.05$, ${ }^{\star *} P<0.01$. Adjusted for energy, only Na+ differs significantly between groups (see text). Electrolytes and energy are in mg and kcal (left axis); macronutrients are in g (right axis). To convert energy in kcal to $\mathrm{kJ}$, multiply by $4 \cdot 184$. $\mathrm{CHO}$, carbohydrate.

\section{Psychophysical assessment of intensity and hedonics of basic tastes}

Intensity. MANCOVA of the four tastes, six concentrations, three groups and sex produced significant interactions of taste with group, taste with sex, the three-way interaction, as well as concentration and taste and the three-way interaction with sex. The group effect $(F(2,122)=5 \cdot 8 ; P=0 \cdot 004)$ suggests ES scoring greater intensity than NS $(P<0 \cdot 001)$ (Fig. 2(a)).

Because taste figures in both significant interactions, each taste was examined separately (MANCOVA). Concentration is significant, as expected, and therefore not detailed.

Intensity of salt solutions of six concentrations, three groups and sex reveals a group effect $(F) 2118)=8 \cdot 1 ; P=0 \cdot 001$ ), with greater intensity in ES compared with NS and EI, respectively $(P<0 \cdot 001$ and $0 \cdot 05)$ (Fig. 3(b)).

Citric acid intensity shows an interaction of group and sex $(F(2,118)=4 \cdot 7 ; P=0 \cdot 011$ ) (see Figs 3(d) and 4(d)), probably because NS women rate it more intense than NS men, with the opposite tendency in the other groups (not shown).

Sucrose intensity differed by group $(F(2,118)=6 \cdot 8 ; P=$ $0 \cdot 002)$, greater in ES compared with NS and EI, respectively $(P<0.001$ and 0.05$)$ (Fig. 3(f), Table 2).

Quinine $\mathrm{HCl}$ intensity differed by group $(F(2,118)=4 \cdot 1$; $P=0.02)$, with EI scoring greater intensity than NS $(P=0.012)$ (Fig. 3(h)). Women and men differed $(F(1,118)$ $=12 \cdot 7 ; P=0.001)$, women rating VAS of quinine intensity as greater than men (58.0 (SE 3.5) v. 41.0 (SE 2.6)), and there was an interaction of sex and concentration $(F(5,590)$ $=2 \cdot 8 ; P=0 \cdot 018)$, because women scored concentrations as more intense than men (Fig. 4(h), Table 2).

Hedonics. MANCOVA of the four tastes, three groups, sex and six concentrations produced significant interactions of concentration with group, with sex and with taste, as well as concentration and taste and the three-way interactions with group and with sex, justifying the individual taste MANCOVA below. A main effect of group $(F(2,121)=6 \cdot 9$; $P=0 \cdot 001)$, with NS rating greater hedonics than ES and EI, respectively $(P=0.021$ and $P<0.002)$, is of unclear significance, occurring only in the lower concentrations which were barely distinguishable (Fig. 2(b)), and a main effect of sex $(F(1,121)=4.8 ; P=0.03)$ appears due to greater aversion in women (Fig. 2(e)).

Hedonics of salt solutions showed interactions of concentration by group $(F(10,585)=3 \cdot 9 ; P=0.000)$ (Fig. 3(a)). An interaction of concentration and $\operatorname{sex}(F(5,585)=4.5 ; P=$ $0 \cdot 000)$ suggests that whereas women showed a dosedependent aversion, men were less responsive to increases in concentration (Fig. 4(a)).

Citric acid hedonics differed by group $(F(2,118)=3 \cdot 2 ; P=$ 0.045), with EI rating highest (Fig. 3(c)). An interaction of sex with concentration $(F(5,590)=4.6 ; P=0.000)$ seemed due to higher rating by men, and dose-dependent aversion in women but not in men (Fig. 4(c)).

Sucrose hedonics showed an interaction of concentration and group $(F(10,590)=4 \cdot 5 ; P=0 \cdot 000)$, although sucrose ${ }^{456}$ showed no significant effects (Fig. 3(e), Table 2).

Quinine $\mathrm{HCl}$ hedonics differed by group $(F(2,118)=8 \cdot 7$; $P=0 \cdot 000)$, with EI most averse and NS least, EI differing from ES and NS $(P=0 \cdot 014$ and $P=0.000$, respectively), and an interaction with concentration, $(F(10,590)=2 \cdot 0 ; P=$ $0 \cdot 035)$, possibly because EI showed a lesser dose-response (Fig. 3(g)). Women rated quinine more aversive than men $(F(1,118)=4 \cdot 0 ; P=0.049)$ (Fig. $4(\mathrm{~g}))$.

Cross-modal control. ANOVA of the greyscale gradation VAS for the three groups, sex and six concentrations showed a three-way interaction $(F(10,605)=2 \cdot 1 ; P=0 \cdot 024)$ (due to EI women scoring dark colours higher), but no significant effects of group or sex, suggesting that VAS is comparable across groups (Fig. 2(c) and (f)).

\section{Sweet and salty tidbits}

MANCOVA (adjusted for age, BMI, smoking) for salty and sweet tidbits, by group and sex showed a significant group 
Table 2. Group comparisons

(Descriptive means with their standard errors)

\begin{tabular}{|c|c|c|c|c|c|c|}
\hline & \multicolumn{2}{|c|}{$\begin{array}{l}\text { New Ethiopian } \\
\text { immigrants } \\
\text { (n 18-20) }\end{array}$} & \multicolumn{2}{|c|}{$\begin{array}{l}\text { Veteran } \\
\text { Ethiopian } \\
\text { immigrant } \\
\text { students } \\
\text { (n 39-30) }\end{array}$} & \multicolumn{2}{|c|}{$\begin{array}{l}\text { Native Israeli } \\
\text { students } \\
\text { (n 80-81) }\end{array}$} \\
\hline & Mean & SE & Mean & SE & Mean & SE \\
\hline Adding salt $†$ & 1.05 & 0.15 & $2 \cdot 12^{*}$ & 0.19 & $2 \cdot 27^{\star}$ & 0.23 \\
\hline Adding sugart & 0.65 & 0.09 & 0.70 & 0.08 & 0.65 & 0.07 \\
\hline Salt in soup (\%) & 1.3 & $0 \cdot 2$ & 1.3 & 0.1 & 1.2 & 0.1 \\
\hline Sucrose in tea (\%) & 8.9 & 1.1 & $10 \cdot 2$ & 0.8 & $10 \cdot 6$ & 0.5 \\
\hline Salt tidbits $\ddagger$ & $7 \cdot 10$ & 1.42 & 15.53 & 2.95 & $15 \cdot 69$ & 1.94 \\
\hline Sweet tidbits $\ddagger$ & $2 \cdot 60^{\star *}$ & 0.61 & 7.07 & 1.67 & 11.12 & 1.56 \\
\hline Salt appetite§ & $49 \cdot 1$ & $2 \cdot 3$ & $65 \cdot 5^{\star \star}$ & 3.4 & $67 \cdot 2^{\star \star}$ & $2 \cdot 2$ \\
\hline $\begin{array}{l}\text { Sweet } \\
\text { preference§ }\end{array}$ & 63.7 & 3.1 & $66 \cdot 2$ & 3.9 & $63 \cdot 6$ & $2 \cdot 6$ \\
\hline Hedonics NaCll & $48 \cdot 9$ & $6 \cdot 0$ & $31 \cdot 2^{\star \star}$ & $3 \cdot 2$ & $30 \cdot 8^{\star \star \star}$ & 1.9 \\
\hline Intensity $\mathrm{NaCl}$ & $60 \cdot 3$ & 4.6 & 71.9 & 3.6 & $63 \cdot 9$ & $2 \cdot 2$ \\
\hline $\begin{array}{l}\text { Hedonics } \\
\text { sucrosell }\end{array}$ & $68 \cdot 1$ & $3 \cdot 3$ & $68 \cdot 4$ & 4.0 & $60 \cdot 6$ & $1 \cdot 7$ \\
\hline Intensity sucrosell & $61 \cdot 8$ & $3 \cdot 3$ & $70 \cdot 9^{*}$ & 3.4 & $60 \cdot 9$ & $2 \cdot 0$ \\
\hline Hedonics citric\|l & 121.8 & $20 \cdot 2$ & 81.6 & $10 \cdot 5$ & 95.7 & $7 \cdot 1$ \\
\hline Intensity citric\| & $40 \cdot 6$ & $6 \cdot 7$ & $27 \cdot 2$ & 3.5 & 31.9 & $2 \cdot 4$ \\
\hline $\begin{array}{l}\text { Hedonics quinine } \\
\text { HCIII }\end{array}$ & $14 \cdot 3$ & $3 \cdot 8$ & $18 \cdot 3$ & $2 \cdot 6$ & $24 \cdot 9^{\star \star}$ & 1.6 \\
\hline $\begin{array}{l}\text { Intensity quinine } \\
\text { HCIII }\end{array}$ & $67 \cdot 0$ & $6 \cdot 9$ & $67 \cdot 3$ & 4.0 & $60 \cdot 7$ & $2 \cdot 5$ \\
\hline
\end{tabular}

Different from unmarked mean except where only one mean is indicated, which refers to the greatest mean difference: ${ }^{*} P<0.05,{ }^{\star \star} P<0.01,{ }^{* \star *} P<0.001$. Significance refers to adjusted values.

† Questionnaire score, $0-3$.

$\ddagger$ Number of tidbits eaten.

$\S$ Sum of above, transformed scores, equally weighted, respectively for salty and sweet.

\|l Mean of three highest concentrations (visual analogue scale). effect $(F(4,242)=2 \cdot 9 ; P=0 \cdot 021)$, with different sweet tidbit intakes $(F(2,121)=5 \cdot 3 ; P=0 \cdot 006)$ (Table 2$)$.

\section{Preferred concentration of $\mathrm{NaCl}$ in soup, and sugar in tea}

MANCOVA of soup and tea, group and sex revealed the expected difference in concentration of salt in soup and sugar in tea (not shown), with an effect of sex $(F(1,122)=$ $6 \cdot 9 ; P=0 \cdot 01)$, because women sweetened their tea less than men $(8.6(\operatorname{SE} 0.7) v .11 \cdot 2(\mathrm{SE} 0 \cdot 6) \%$ ).

\section{Evaluation of salt appetite}

Salt appetite differed by group (corrected for age, smoking and BMI $(F(2,119)=5 \cdot 3 ; P=0 \cdot 006)$, lowest in EI and highest in NS. Sweet preference did not differ significantly between groups (Table 2).

\section{Biography of putative sodium loss}

Lifetime tendencies for vomiting, diarrhoea, dehydration or their composite score did not correlate with salt appetite or sweet preference. The EI group did not have their mothers in the country to contact. ES mothers reported higher measures of vomiting and distress in the second and third trimesters than NS mothers (Kruskall-Wallis, $P<0 \cdot 05$, data not shown).

\section{6-n-Propylthiouracil responses}

ANOVA showed that PROP responses differed by group ( $F$ $(2,123)=5 \cdot 0 ; \quad P=0 \cdot 008) \quad($ Table 1$)$, and were higher in (a)

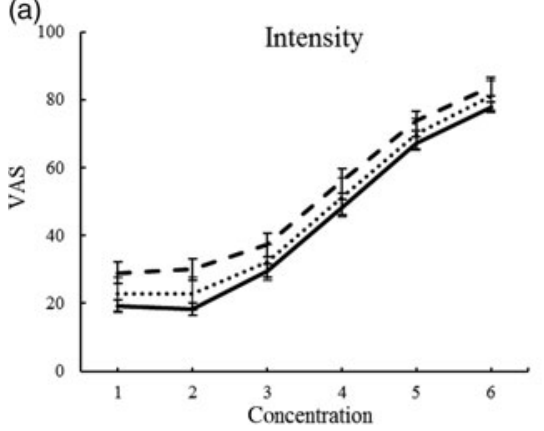

(d)

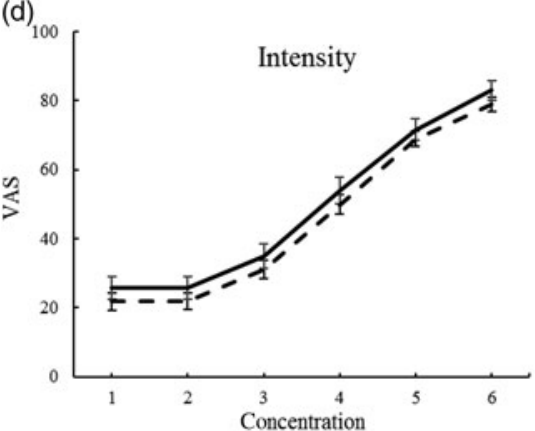

(b)

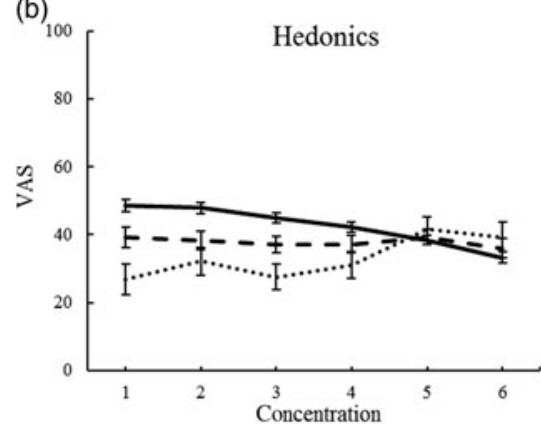

(e)

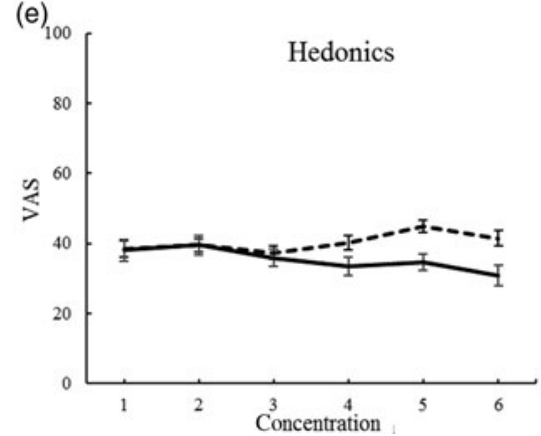

(c)

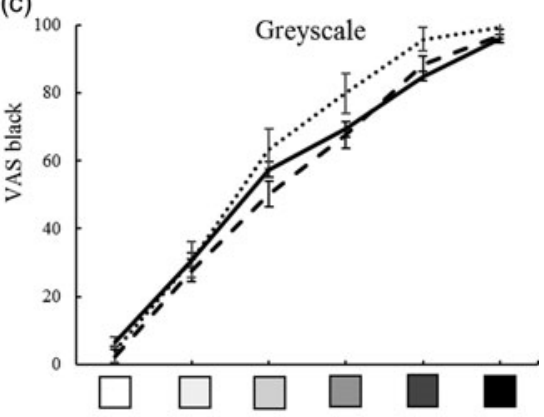

(f)

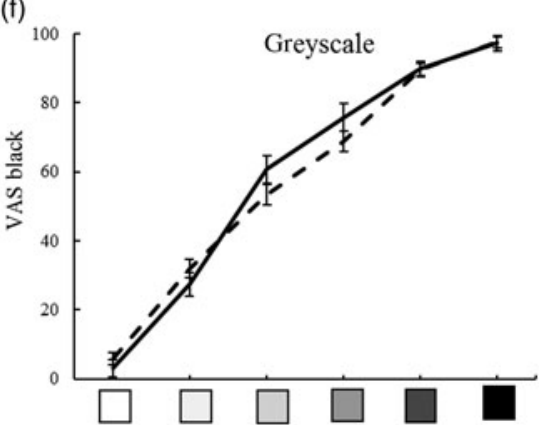

Fig. 2. Overall responses to basic tastes and cross-modal greyscale control by group ((a), (b), (c); -., new Ethiopian immigrants; ---, veteran Ethiopian immigrant students; - , native Israeli students) and sex ((d), (e), (f); ---, men; - , women). Significant effects for (a), (b) and (e) are detailed in the text. Values are means, with standard errors represented by vertical bars. VAS, visual analogue scale. 
(a)

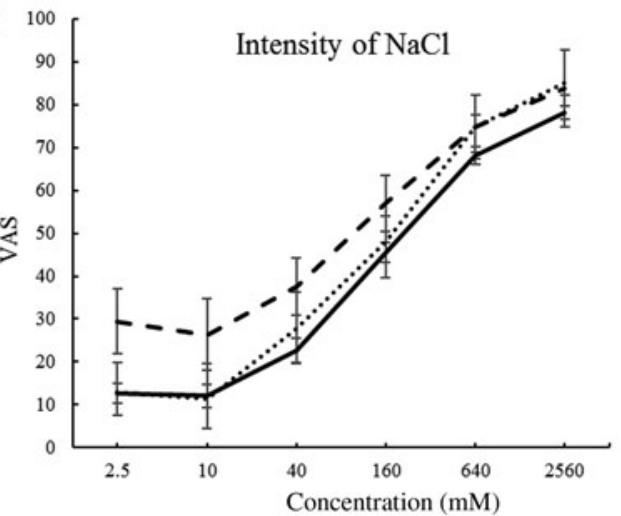

(c)

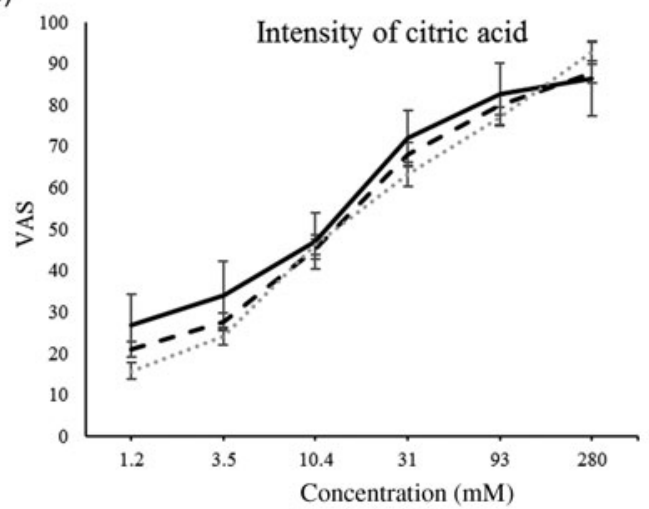

(e)

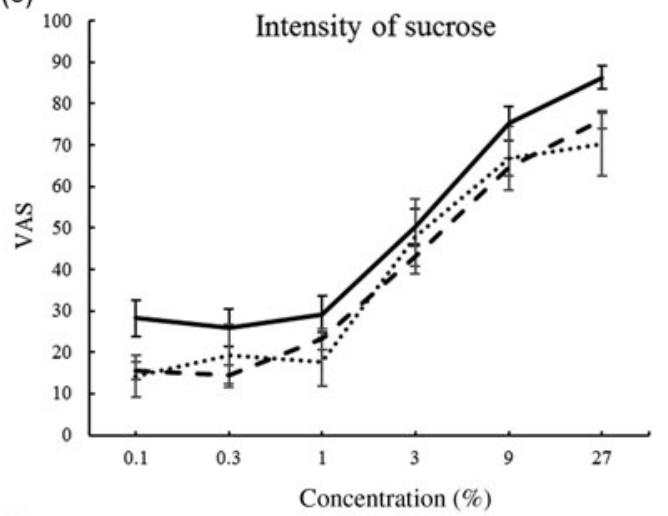

(g)

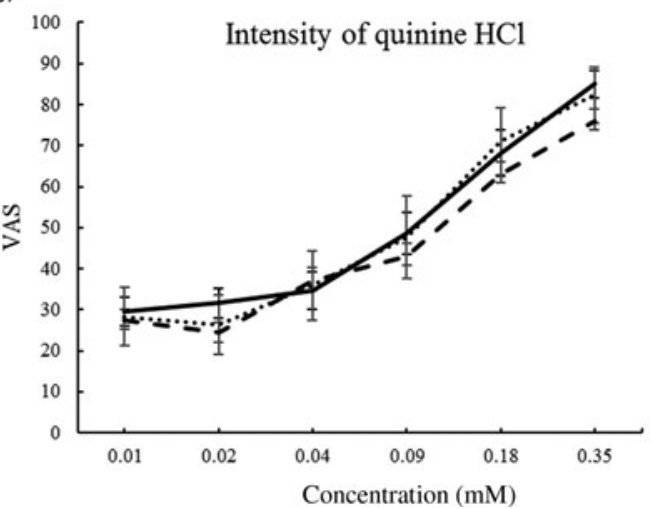

(b) 100

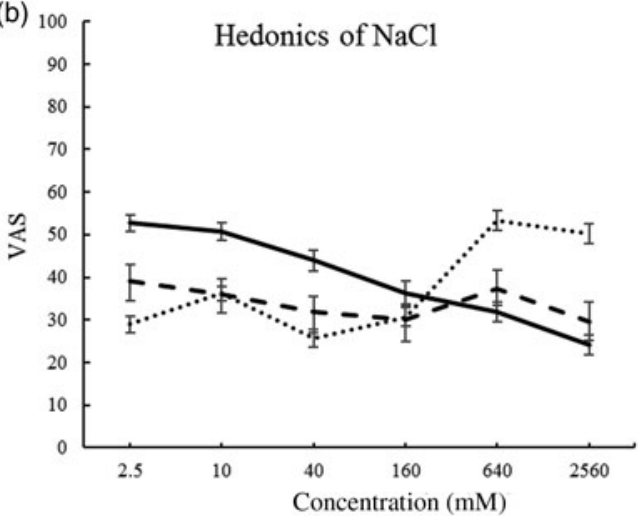

(d)

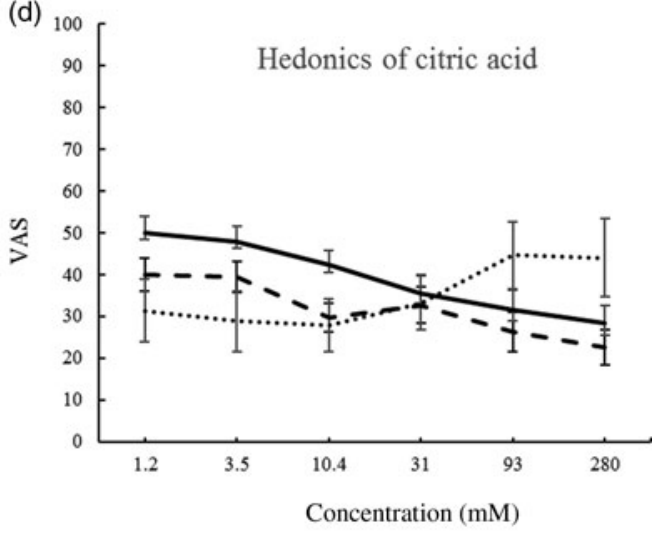

(f)

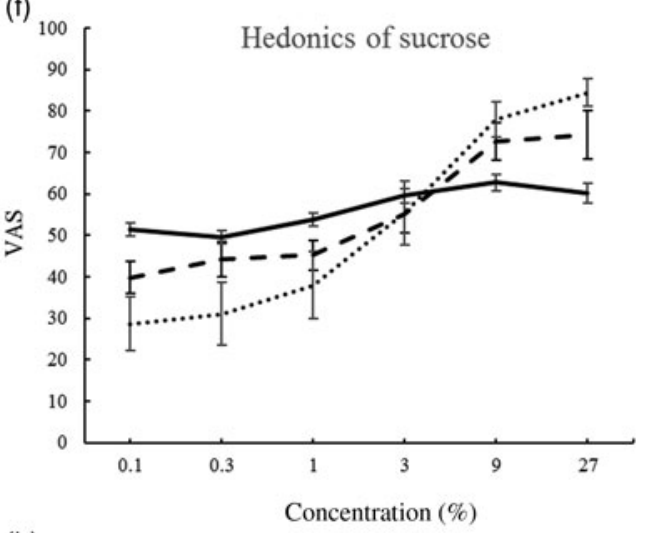

(h)

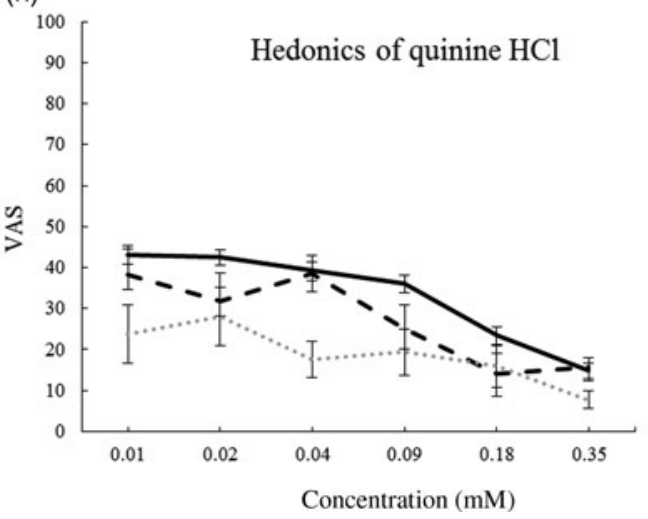

Fig. 3. Intensity and hedonics of four basic tastes by group ( $\cdots$, new Ethiopian immigrants; ---, veteran Ethiopian immigrant students; - , native Israeli students). There were significant effects for group and/or group interactions for all the graphs, which are detailed in the text. Values are means, with standard errors represented by vertical bars. VAS, visual analogue scale. 
(a)

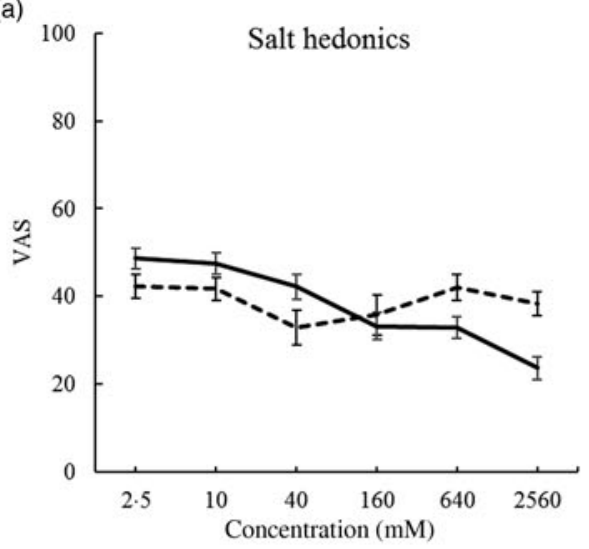

(c)

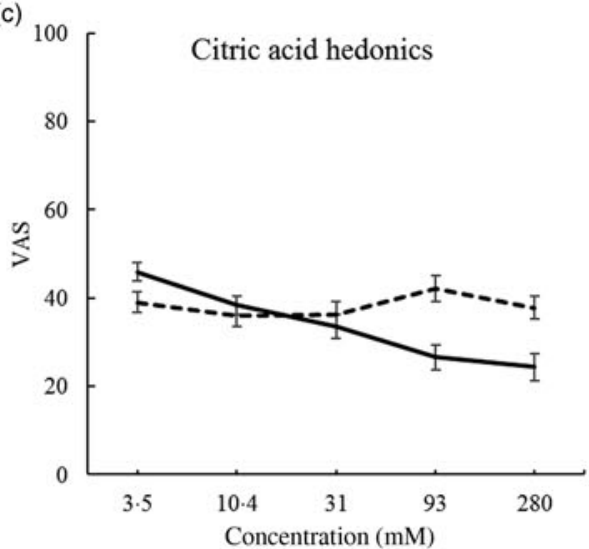

(e)

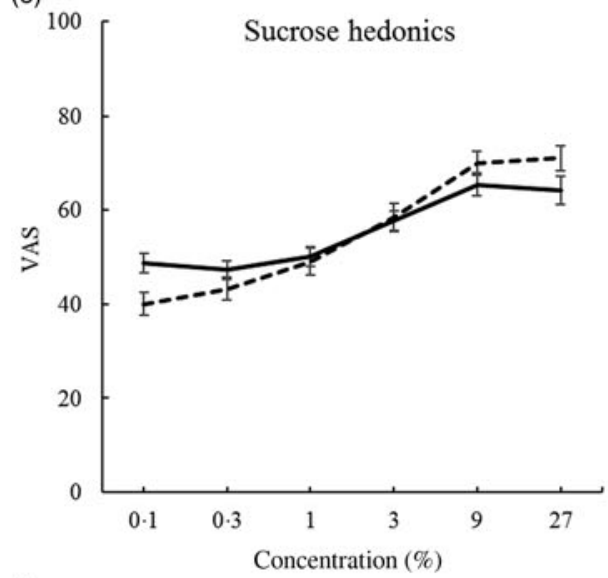

(g)

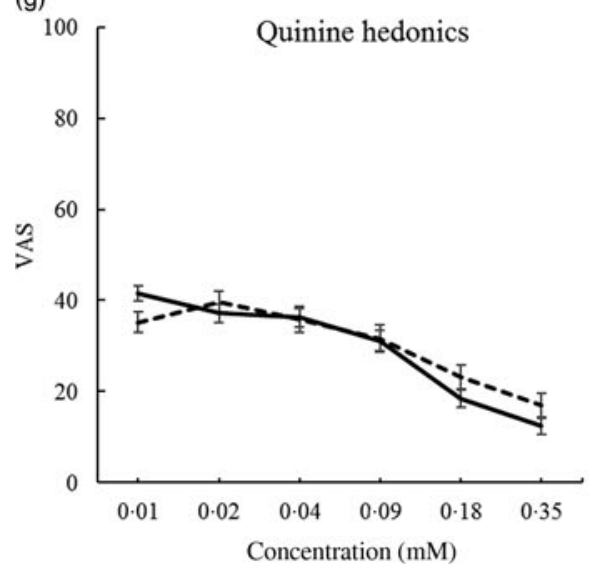

(b)

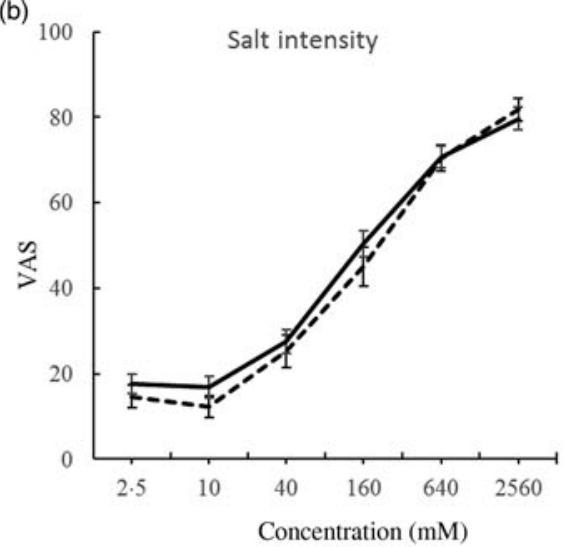

(d)

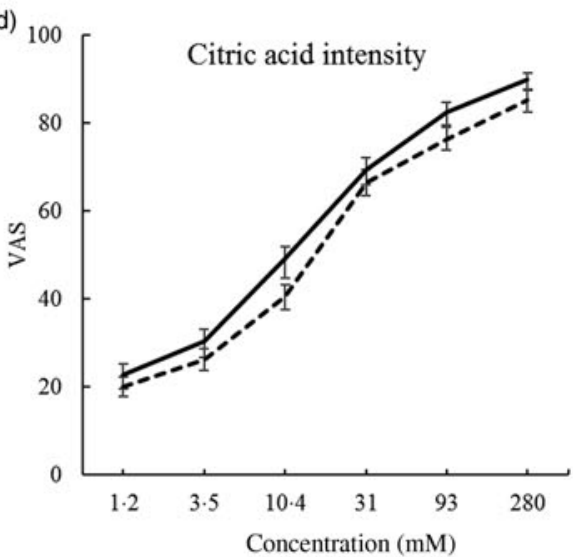

(f)

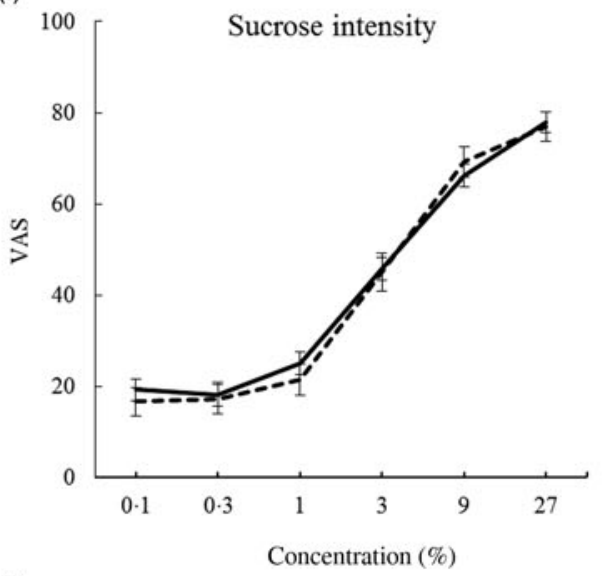

(h)

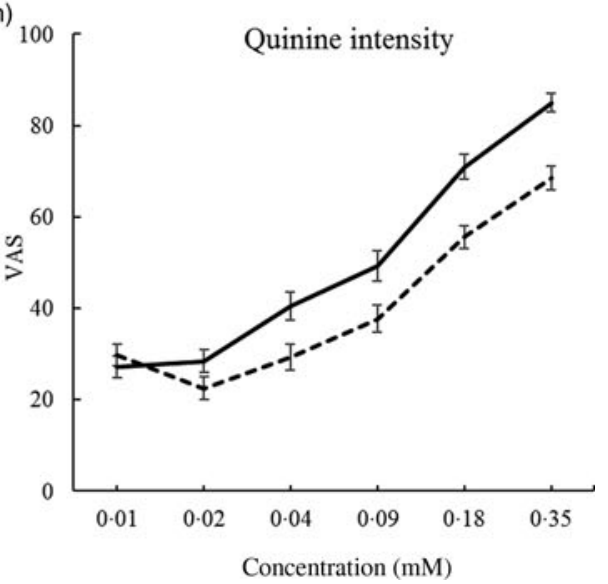

Fig. 4. Intensity and hedonics of four basic tastes in men (--) and women (-). Significant effects and/or interactions for sex for (a), (c), (d) and (h) are detailed in the text. Values are means, with standard errors represented by vertical bars. VAS, visual analogue scale. 
women $(F(1,123)=5 \cdot 0 ; P=0 \cdot 027 ; 71 \cdot 1 \quad($ SE $6 \cdot 2) v .53 \cdot 7(\mathrm{SE}$ $4 \cdot 7)$ ).

PROP responses correlated with intensity and hedonics of VAS for the mean three highest concentrations as follows:

For intensity of salt ${ }^{456}, r_{\mathrm{s}} 0 \cdot 175, P=0 \cdot 049, n 127$.

For intensity of sucrose ${ }^{456}, r_{\mathrm{s}} 0 \cdot 171, P=0 \cdot 055, n 127$, and hedonics for men, $r_{\mathrm{s}} 0 \cdot 394, P=0 \cdot 007, n 46$ (but inversely for NS women, $\left.r_{\mathrm{s}}-0 \cdot 366, P=0 \cdot 005, n 58\right)$.

Citric acid ${ }^{456}$ intensity for men, $r_{\mathrm{s}} 0 \cdot 313, P=0 \cdot 034, n 36$.

Notably, PROP scores did not correlate with intensity or hedonics of quinine $\mathrm{HCl}$, nor with any of the test, dietary or demographic measures.

6-n-Propylthiouracil taster type. There were 10-12\% nontasters in each group (unlike the $30 \%$ reported for the USA, but consistent with the 3-40\% reported worldwide ${ }^{(16,22)}$, resulting in samples too small for reliable analysis by group. There was no significant influence on any of the dietary and test variables, which did not differ by sex.

\section{Fungiform papilla density, taste intensity and hedonics}

MANCOVA for two groups (EI were not assessed) and sex showed no significant effects, Nevertheless, with sex omitted, lingual fungiform papillae density tended to be lower in ES than NS $(F(1,98)=4 \cdot 8 ; P=0.031)$ (Table 1).

There were no significant correlations of papilla density by group or sex, with overall, or individual, basic taste psychophysics, intensity ${ }^{456}$, or hedonics ${ }^{456}$. There were significant correlations in specific subgroups. For salt ${ }^{456}$, ES showed a correlation with hedonics $\left(r_{\mathrm{s}} 0.483, P=0.009, n 28\right)$, and for ES women, inverse with intensity $\left(r_{\mathrm{s}}-0.596, P=0.007, n\right.$ 19). For citric acid, women showed inverse correlations with hedonics $\left(r_{\mathrm{s}}-0 \cdot 317, P=0 \cdot 018, n 55\right)$. For quinine ${ }^{456}$ hedonics, there was a correlation for NS men $\left(r_{\mathrm{s}} 0.585, P=\right.$ $0 \cdot 007, n$ 20). There were no significant correlations with sucrose $^{456}$.

\section{Discussion}

Across two immigrant and one native group of young people, graded by increasing familiarity with the dominant diet, the major dietary difference is increased intake of energy, fat, and, most prominently, $\mathrm{Na}^{+}$. Also trending from EI, to ES, to NS, were decreasing PROP responses, and hedonics of salt, sucrose and citric acid (intensity roughly following hedonics inversely), whereas adding salt, and eating tidbits in the laboratory, and anterior lingual fungiform papilla density increased. Together, these changes could reflect dietary acculturation, increasing overall intake, $\mathrm{Na}^{+}$in particular, accompanied by decreasing taste sensitivity, and changes in sensory perception and preference in these Ethiopian immigrants.

\section{New immigrant diet and sodium appetite}

The new immigrant (EI) diet in the immigrant centre comprised dinner prepared and served in the cafeteria, standard
Israeli fare of the time. Immigrants prepared breakfast and lunch daily, and weekend dinner, in their apartments from bought food for which they received an allowance. They reported that $7.4 \%$ of the foods they ate were purely Ethiopian, but some of the foods are common to both Ethiopian and Israeli diets, such as cooked vegetables and meat, fruit, etc. Therefore, EI dietary differences from ES and NS are probably conservative in comparison with the original Ethiopian diet ${ }^{(40)}$. More interestingly, their choice of foods within these constraints showed up as the difference from the other groups, most notably lower dietary $\mathrm{Na}^{+}$intake. This is supported by EI liking scores, where Ethiopian staples scored high (all eight of twenty-four most liked foods), whereas common Israeli foods, such as pizza and ice-cream, scored low, suggesting preference guided their choices. Only in EI was there was a robust inverse correlation between the $\mathrm{Na}^{+}$content of food items and liking scores, a salt adding score less than half of the other groups (Table 2), and only one EI adding 'much' salt compared with over $40 \%$ of ES and NS.

\section{Sodium appetite}

Dietary $\mathrm{Na}^{+}$intake in the sample was relatively high, but similar to other groups we have studied ${ }^{(29,30,32,34)}$. Intake of $\mathrm{Na}^{+}$ is not a unitary phenomenon; it comprises untasted $\mathrm{Na}^{+}$content of food, salting of food, which is partially a motor habit, preference for salty snacks, preference for salty foods, etc. ${ }^{(32,41,42)}$. Thus, EI show an inverse correlation between liking and $\mathrm{Na}^{+}$content of food items, have a lower dietary $\mathrm{Na}^{+}$intake, salt less than half of the other groups. However, in seeming contradiction, EI scored increased salt hedonics. In the tests they did not differ eating salty tidbits, or salting the soup, but overall, $\mathrm{Na}^{+}$appetite progressed with acculturation. The dissociation between salt preference and intake is well documented ${ }^{(14,18,23,25,32)}$. Indeed, Ethiopians season food during preparation, not at table, consistent with the low EI salting we report, yet an Ethiopian saying illuminates their love of salt: 'a person who does not behave appropriately according to practice, is like food without salt ${ }^{(43)}$.

Finally, the marked progression of $\mathrm{Na}^{+}$appetite with dietary acculturation seems specific, insofar as sweet preference does not differ.

\section{Taste sensory differences}

PROP responses differ by group, which were highest in EI and lowest in NS (Table 1), were higher in women, and, particularly in the immigrant groups, correlate with intensity of oral sprays of salt, sucrose and, in men, citric acid and hedonics of sucrose. Notably, there is no correlation with the bitter taste of quinine $\mathrm{HCl}^{(24,44,45)}$. These responses in part are consistent with previous reports of higher scores in women, and correlations with intensity or hedonics of salt and sucrose ${ }^{(16,32,38)}$.

Lingual fungiform papilla density was not examined in EI, for which the procedure was too invasive. Papilla density was higher in NS than ES, and did not relate consistently to any of the measures, although subgroup analyses suggested 
that papilla density correlates inversely with intensity of salt, citric acid and quinine, particularly in women.

No relationship was found between PROP and papilla density, and neither of these predicted salt appetite, dietary intake, BMI, or any of the other tests and measures, broadly in line with variability in PROP response, and the probably marginal contribution to intake ${ }^{(14,22-25)}$.

The overall tendency for PROP responses and papilla density to be progressive from EI and ES to NS could suggest changes in taste perception over increasing exposure to native diet. In turn, this raises the possibility of changes with dietary acculturation in sensory neural and (epi)genetic substrates in papilla $^{(38,46)}$ and, intriguingly, PROP response. Differences in PROP response with overall diet have been reported previously (although the authors favoured the opposite causality) ${ }^{(13)}$. An altered microbiome may also contribute to changes in papilla function ${ }^{(47)}$.

Categorisation of PROP responses into taster type provided no additional useful results.

\section{$B M I$}

New immigrants had the lowest BMI (age-adjusted) with similar progression through the groups as repeatedly reported (Table 1$)^{(2,7,48)}$. NS men differed from ES and EI men $(24 \cdot 7$ (SE 0.7), 21.7 (SE 1.1), 20.0 (SE 0.9); $P=0 \cdot 015$ and 0.000, respectively), whereas women did not differ by group. The data contrast with the alarming data on obesity and ill-health in this community, even in similarly 10 - to 15 -year veteran Ethiopian immigrants ${ }^{(8,11)}$, possibly because our sample was young and quite homogeneous.

\section{Sex differences}

Some psychophysical responses and some taste sensory variables differed by sex. Primarily, women rated quinine as more intense, and were more averse to the tastes, particularly for citric acid and quinine, with a similar tendency for salt ${ }^{(38,49)}$. Their hedonic response appears concentrationdependent, whereas men tended to flatter curves, suggesting poorer discrimination of concentration (Figs 2 and 4).

PROP response was greater in women, but not papillae density. PROP in men predicted intensity of citric acid, and sucrose hedonics. Sex and group interactions for PROP differed by taste, hedonics and intensity, but despite some correlations, no clear pattern was discernable, consistent with the diverse results of other studies ${ }^{(16,24,45)}$.

Women sweetened their tea more, and reported lower alcohol intake and less activity. We found no relationship with week of menstrual cycle (data not shown) ${ }^{(49)}$.

\section{Limitations}

Group sizes for EI and ES were determined by availability, and criteria of age, and time since immigration, although power was adequate (above), and analyses comparing Ethiopians as a group with NS ( $n 50$ and $n$ 82) confirmed the differences.
The cross-sectional design limited inferences about temporal processes, but comparisons at a single time-point excluded temporal changes in diet due to changing food preferences, trends, price, availability, etc. Cross-sectional comparisons of urbanisation within countries of origin revealed similar patterns of dietary acculturation and health consequences, supporting the suggestion that dietary differences may reflect acculturation, and length of residence has been suggested to reflect the sum total of an immigrant's experiences and exposures in their host society that make an impact on health ${ }^{(50,51)}$.

Whether differences relate to immigration or ethnicity cannot be determined from our data; however, in Ethiopia, the Jewish community was circumscribed in diet, region, ethnicity and religion, making it unlikely that EI and ES differed substantially in origin ${ }^{(40,43)}$.

Dietary questionnaires are of limited validity, as is the assessment of $\mathrm{Na}^{+}$by any means ${ }^{(52)}$. Nevertheless, used to compare groups, as in the present study, absolute values are a lesser concern.

\section{Conclusions}

Our findings confirm the increase in intake during dietary acculturation of immigrants to more affluent environments. More than previous studies, our results indicate that increased salt appetite may be prominent in dietary acculturation, as it is for Ethiopian immigrants to Israel. While diet changes may alter taste responses and psychophysics ${ }^{(14,39,46,48,53)}$, the finding that fungiform lingual papillae density, and the genetic response to PROP are altered, is novel.

The study adds Ethiopians to the immigrant community diets most often studied ${ }^{(1,3)}$. Ethiopian immigrant communities total some 1.5 million, over half in the USA, Saudi Arabia and Israel, the rest in Canada, Europe, Australia and Ethiopia's neighbours, but Ethiopian dietary acculturation has been sparsely studied ${ }^{(11,12,40,54-57)}$.

Understanding dietary acculturation is of interest for many reasons, among them the opportunity to improve healthy eating among immigrants, inter alia by maintaining the healthy aspects of their traditional diets (for Ethiopians - less fat and $\mathrm{Na}^{+}$), helping them anticipate the process and challenge of acculturation, and their vulnerability to the increased disease burden of diets of affluence $e^{(4-8,10-12)}$. Here we show that $\mathrm{Na}^{+}$ intake is greatly increased, which is useful to focus dietary advice, because excess $\mathrm{Na}^{+}$may contribute to the health ailments afflicting immigrants ${ }^{(1)}$.

In practice, these immigrants' nutrition is healthier in its low fat and $\mathrm{Na}^{+}$, suggesting that nutritional advice should focus on preservation, as well as prevention, and it may also enrich health and variety in the dominant $\operatorname{diet}^{(6,8)}$. Other useful insights may also be gained. For example, the fact that these immigrants find salt more hedonic but eat less of it, whereas natives find it less hedonic but eat more of it, might suggest that the high native $\mathrm{Na}^{+}$intake may be due to reduced sensitivity to the taste of $\mathrm{Na}^{+}$, which may be restored ${ }^{(12,13,46)}$. Similar taste sensory adaptations to changing diet may occur during dieting, or after bariatric surgery, etc. ${ }^{(12,13,46,53)}$. 
Such knowledge can guide preferences toward a healthier diet for all.

\section{Acknowledgements}

We thank Aysha Agbaria, Aviv Bracha, Raneen Dally Farah, Areen Khair, Felix Portnoi, Einat Shalev, Avigail Yonas and Galit Zach for their contribution to the study, and Efrat Yaskil, $\mathrm{PhD}$, for statistical advice. The study was supported by the Israel Science Foundation (902/00-2 and 7481478) and the Israel Ministry of Health (1043-3-00000).

H. D.-N. evaluated the research with EI, providing the cultural insights and translations, and wrote the relevant sections together with M. L. Both authors contributed to interpretation of data; drafting of the manuscript and approved the final version of the manuscript.

There were no conflicts of interest.

\section{References}

1. Kershaw KN, Giacinto RE, Gonzalez F, et al. (2016) Relationships of nativity and length of residence in the U.S. with favorable cardiovascular health among Hispanics/Latinos: The Hispanic Community Health Study/Study of Latinos (HCHS/SOL). Prev Med 89, 84-89.

2. Antecol H \& Bedard K (2006) Unhealthy assimilation: why do immigrants converge to American health status levels? Demography 43, 337-360.

3. Gilbert PA \& Khokhar S (2008) Changing dietary habits of ethnic groups in Europe and implications for health. Nutr Rev 66, 203 215.

4. Okafor MTC, Carter-Pokras OD \& Zhan M (2014) Greater dietary acculturation (dietary change) is associated with poorer current selfrated health among African immigrant adults. J Nutr Educ Behav 46, 226-235.

5. Rosenthal T (2014) The effect of migration on hypertension and other cardiovascular risk factors: a review. J Am Soc Hypertens 8, 171-191.

6. Satia-Abouta J, Patterson RE, Neuhouser ML, et al. (2002) Dietary acculturation: applications to nutrition research and dietetics. $J \mathrm{Am}$ Diet Assoc 102, 1105-1118.

7. Vargas P \& Jurado LF (2015) Dietary acculturation among Filipino Americans. Int J Environ Res Public Health 13, ijerph13010016.

8. Jaffe A, Giveon S, Wulffhart L, et al. (2016) Diabetes among Ethiopian immigrants to Israel: exploring the effects of migration and ethnicity on diabetes risk. PLOS ONE 11, e0157354.

9. Delisle H (2010) Findings on dietary patterns in different groups of African origin undergoing nutrition transition. Appl Physiol Nutr Metab 35, 224-228.

10. Reuven Y, Dreiher J \& Shvartzman P (2016) The prevalence of diabetes, hypertension and obesity among immigrants from East Africa and the former Soviet Union: a retrospective comparative 30-year cohort study. Cardiovasc Diabetol 5, 15-74.

11. Regev-Tobias H, Reifen R, Endevelt R, et al. (2012) Dietary acculturation and increasing rates of obesity in Ethiopian women living in Israel. Nutrition 28, 30-34.

12. Oswald R \& Gerber-Medhin M (1978) Westernization of diet and serum lipids in Ethiopians. Am J Clin Nutr 31, 1028-1040.

13. Stevenson RJ, Boakes RA, Oaten MJ, et al. (2016) Chemosensory abilities in consumers of a Western-style diet. Chem Senses 41, 505-513.

14. DeSimone JA, Beauchamp GK, Drewnowski A, et al. (2013) Sodium in the food supply: challenges and opportunities. Nutr Rev 71, 52-59.
15. Choi SE \& Chan J (2015) Relationship of 6- $n$-propylthiouracil taste intensity and chili pepper use with body mass index, energy intake, and fat intake within an ethnically diverse population. J Acad Nutr Diet 115, 389-396.

16. Duffy VB \& Bartoshuk LM (2000) Food acceptance and genetic variation in taste. J Am Diet Assoc 100, 647-655.

17. Duffy VB, Hayes JE, Davidson AC, et al. (2010) Vegetable intake in college-aged adults is explained by oral sensory phenotypes and TAS2R38 genotype. Chemosens Percept 3, 137-148.

18. Hayes JE, Sullivan BS \& Duffy VB (2010) Explaining variability in sodium intake through oral sensory phenotype, salt sensation and liking. Physiol Behav 100, 369-380.

19. Bartoshuk LM, Duffy VB \& Miller IJ (1994) PTC/PROP tasting: anatomy psychophysics and sex effects. Physiol Behav 56, 11651171.

20. Keller KL, Steinmann L, Nurse RJ, et al. (2002) Genetic taste sensitivity to 6-n-propylthiouracil influences food preference and reported intake in preschool children. Appetite 38, 3-12.

21. Robino A, Mezzavilla M, Pirastu N, et al. (2014) A populationbased approach to study the impact of PROP perception on food liking in populations along the Silk Road. PLOS ONE 9, e91716.

22. Tepper BJ (1998) 6-n-Propylthiouracil: a genetic marker for taste, with implications for food preference and dietary habits. Am J Hum Genet 63, 1271-1276.

23. Drewnowski A, Henderson S, Ahlstrom D, et al. (1996) Salt taste perceptions and preferences are unrelated to sodium consumption in healthy older adults. J Am Diet Assoc 96, 471-475.

24. Drewnowski A, Henderson SA \& Cockroft JE (2007) Genetic sensitivity to 6-n-propylthiouracil has no influence on dietary patterns, body mass indexes, or plasma lipid profiles of women. J Am Diet Assoc 107, 1340-1348.

25. Mattes RD (2004) PROP taster status: dietary modifier marker or misleader. In Genetic Variation in Taste Sensitivity, pp. 229-250 [J Prescott and BJ Tepper, editors]. New York: CRC Press.

26. Garcia-Bailo B, Toguri C, Eny KM, et al. (2009) Genetic variation in taste and its influence on food selection. OMICS 13, 69-80.

27. The Knesset, The Research and Information Center (2011) Methods of Immigrant Absorption in Israel. Presented to the Committee on Immigration, Absorption and Diaspora Affairs. https://www.knesset.gov.il/mmm/data/pdf/me02775.pdf (accessed November 2017).

28. Leshem M (1998) Salt preference in adolescence is predicted by common prenatal and infantile mineral of fluid loss. Physiol Behav 63, 699-704.

29. Leshem M, Saadi A, Alem N, et al. (2008) Enhanced salt appetite, diet and drinking in traditional Bedouin women in the Negev. Appetite 50, 71-82.

30. Kochli A, Rakover Y \& Leshem M (2005) Salt appetite in patients with CAH-21-OH deficiency (congenital adrenal hyperplasia). Am J Physiol Regul Integr Comp Physiol 288, R1673-R1681.

31. Stone LJ \& Pangborn RM (1990) Preferences and intake measures of salt and sugar, and their relation to personality traits. Appetite 15, 63-79.

32. Leshem M (2009) Biobehavior of the human love of salt. Neurosci Biobehav Rev 33, 1-17.

33. Shirazki A, Weintraub Z, Reich D, et al. (2007) Lowest neonatal serum sodium predicts sodium intake in low birth weight children. Am I Physiol Regul Integr Comp Physiol 292, R1683-R1689.

34. Leshem M (2009) The excess salt appetite of humans is not due to sodium loss in adulthood. Physiol Behav 98, 331-337.

35. Crystal SR \& Bernstein IL (1995) Morning sickness: impact on offspring salt preference. Appetite 25, 231-240.

36. Bartoshuk LM, Duffy VB, Lucchina LA, et al. (1998) PROP (6- $n$-propylthiouracil) supertasters and the saltiness of $\mathrm{NaCl}$. Ann N Y Acad Sci 855, 793-796.

37. Miller IJ Jr \& Reedy FE Jr (1990) Variations in human taste bud density and taste intensity perception. Physiol Behav 47, 1213-1219. 
38. Sato K, Endo S \& Tomita H (2002) Sensitivity of three loci on the tongue and soft palate to four basic tastes in smokers and nonsmokers. Acta Otolaryngol Suppl 122, 74-82.

39. Fischer ME, Cruickshanks KJ, Schubert CR, et al. (2013) Factors related to fungiform papillae density: the Beaver Dam Offspring Study. Chem Senses 38, 669-677.

40. Hardoff D, Nudelman A \& Chigier E (1999) Changes in the eating habits of Ethiopian adolescent immigrants. Int J Adolesc Med Health 11, 39-45.

41. Shepherd R, Farleigh CA \& Land DG (1984) Preference and sensitivity to salt taste as determinants of salt intake. Appetite 5, 187-197.

42. Greenfield H, Maples J \& Wills RBH (1983) Salting of food - a function of hole size and location of shakers. Nature 301, 331-332.

43. Koiller M (2014) 'Food, honor and love' - changes in the culture of food following the Ethiopian immigration to Israel. Israelis 6 , 95-122 (Hebrew).

44. Delwiche JF, Buletic Z \& Breslin PA (2001) Relationship of papillae number to bitter intensity of quinine and PROP within and between individuals. Physiol Behav 74, 329-337.

45. Webb J, Bolhuis DP, Cicerale S, et al. (2015) The relationships between common measurements of taste function. Chemosens Percept 8, 11-18.

46. Noel CA, Cassano PA \& Dando R (2017) College-aged males experience attenuated sweet and salty taste with modest weight gain. J Nutr 147, 1885-1891.

47. Lyte M, Fodor AA, Chapman CD, et al. (2016) Gut microbiota and a selectively bred taste phenotype, a novel model of microbiomebehavior relationships. Psychosom Med 78, 610-619.

48. Menigoz K, Nathan A, Heesch KC, et al. (2018) Ethnicity, length of residence, and prospective trends in body mass index in a national sample of Australian adults (2006-2014). Ann Epidem 28, 160-168.

49. Duffy VB, Bartoshuk LM, Striegel-Moore, et al. (1998) Taste changes across pregnancy. Ann N Y Acad Sci 855, 805-809.

50. Feyie B, Esayas KG \& Kifle WH (2014) Prevalence of hypertension and associated factors in Bedele town, southwest Ethiopia. Ethiop J Health Sci 24, 21-26.

51. Twagirumukiza M, De Bacquer D, Kips JG, et al. (2011) Current and projected prevalence of arterial hypertension in sub-Saharan Africa by sex, age and habitat, an estimate from population studies. J Hypertens 29, 1243-1252.

52. Titze J (2017) Estimating salt intake in humans, not so easy! Am J Clin Nutr 105, 1253-1254.

53. Pepino MY, Bradley D, Eagon JC, et al. (2014) Changes in taste perception and eating behavior after bariatric surgery-induced weight loss in women. Obesity 22, E13-E20.

54. Terrazas AM (2007) Beyond regional circularity: the emergence of an Ethiopian diaspora. Migration Information Source. http://www. migrationpolicy.org/article/beyond-regional-circularity-emergenceethiopian-diaspora/ (accessed February 2017).

55. Central Bureau of Statistics (2016) CBS, Statistical Abstract of Israel. Jews, by Country of Origin and Age. http://www.cbs.gov.il/reader/ shnaton/templ_shnaton_e.html?num_tab=st02_08x\&CYear $=2016$ (accessed June 2017).

56. Africa News (2017) Thousands of Ethiopians return home from Saudi Arabia. http://www.africanews.com/2017/08/01/thousands-of-ethiopians-return-home-from-saudi-arabia// (accessed December 2017).

57. Wikipedia (2018) Ethiopian Canadians. https://en.wikipedia.org/ wiki/Ethiopian_Canadians (accessed January 2018). 